\title{
El desafío de controlar las enfermedades transmitidas por alimentos: bacteriófagos como una nueva herramienta biotecnológica
}

\author{
Denisse Jorquera, Nicolás Galarce y Consuelo Borie
}

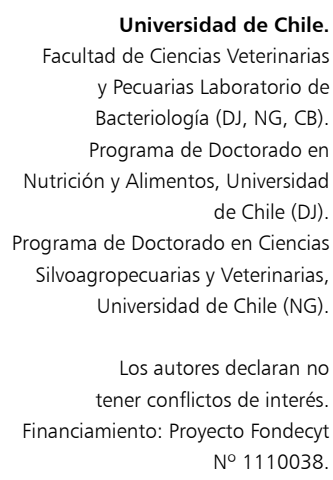

Universidad de Chile. Facultad de Ciencias Veterinarias

y Pecuarias Laboratorio de

Bacteriología (DJ, NG, CB).

Programa de Doctorado en Nutrición y Alimentos, Universidad de Chile (DJ).

Programa de Doctorado en Ciencias Silvoagropecuarias y Veterinarias,

Universidad de Chile (NG).

Los autores declaran no tener conflictos de interés. Financiamiento: Proyecto Fondecyt № 1110038

Recibido: 8 de enero de 2015 Aceptado: 9 de septiembre de 2015

Correspondencia a: Consuelo Borie Polanco cborie@uchile.cl

\section{The challenge of controlling foodborne diseases: bacteriophages as a new biotechnological tool}

Foodborne diseases are an increasing public health issue, in which bacterial pathogens have a transcendental role. To face this situation, the food industry has implemented several control strategies, using in the last decade some biotechnological tools, such as direct application of bacteriophages on food, to effectively control bacterial pathogens. Their bactericidal and safe properties to humans and animals have been widely described in the literature, being nowadays some bacteriophage-based products commercially available. Despite this, there are so many factors that can interfere in their biocontrol effectiveness on food, therefore is essential to consider these factors before their application. Thus, the optimal bacterial reduction will be achieved, which would produce a safer food. This review discusses some factors to consider in the use of bacteriophages as biocontrol agents of foodborne pathogens, including historical background, taxonomy and biological description of bacteriophages, and also advantages, disadvantages, and considerations of food applications.

Key words: Foodborne diseases, biocontrol, bacteriophages, public health.

Palabras clave: Enfermedades transmitidas por alimentos, bio-control, bacteriófagos, salud pública.

\section{L} a inocuidad alimentaria, definida como "la garantía de que los alimentos no causarán daño al consumidor cuando se preparen y/o consuman de acuerdo con el uso al que se destinan", es un tema complejo que posee un impacto en todos los segmentos de la sociedad, abarcando consumidores, gobierno, industria alimentaria y la academia. Aunque los esfuerzos se han centrado en aumentar la producción de alimentos sanos y seguros, utilizando nuevas tecnologías, buenas prácticas de manufactura, control de calidad y medidas de higiene y seguridad, tales como la implementación del análisis de riesgo y puntos críticos de control (HACCP), las enfermedades transmitidas por alimentos (ETA) siguen siendo responsables de altos niveles de morbilidad y en algunos casos de mortalidad, tanto en países desarrollados como en aquellos en vías de desarrollo, generando cuantiosas pérdidas para la salud pública, la salud animal y la industria alimentaria ${ }^{2-4}$. Se han descrito alrededor de 250 agentes causantes de ETA, entre los que se incluyen agentes químicos, físicos y biológicos, siendo los agentes biológicos de origen bacteriano, particularmente Salmonella spp., Listeria monocytogenes, Campylobacter spp., Shigella spp. y Escherichia coli O157:H7 los mayormente involucrados en brotes ${ }^{4-6}$. La globalización del mercado, la introducción de nuevos productos y procesos de fabricación, junto a la creciente demanda por alimentos listos para el consumo, requieren por lo general, de una cadena de producción más larga y compleja, lo que aumenta el riesgo de contaminación microbiológica.

La magnitud global de las ETA es mayoritariamente desconocida, existiendo en muchos países sólo estimaciones de su impacto. Así, durante el año 2012, en E.U.A. se notificaron 831 brotes de ETA, resultando en 14.972 personas afectadas, 794 hospitalizaciones y 23 muertos. El agente etiológico fue confirmado en $69 \%$ de los brotes, siendo Salmonella spp., responsable de $26 \%$ de ellos, donde el serotipo Enteritidis fue el principal involucrado (26\%). En menor medida se identificó a Campylobacter spp., E. coli shiga-toxigénica (ECST), Clostridium perfringens, Vibrio parahaemolyticus, C. botulinum, $L$. monocytogenes y Staphylococcus aureus. Cabe destacar que los datos señalan un sostenido aumento de los brotes producidos por Campylobacter $\mathrm{spp}^{7}$. De acuerdo a los últimos datos oficiales disponibles, en la Unión Europea, se registraron 5.648 brotes de ETA durante el año 2011, resultando en 69.553 casos, 7.125 hospitalizados y 93 muertos $^{8}$. La mayoría de los reportes fueron producto de Salmonella spp., seguido por Campylobacter y algunos virus; sin embargo, los brotes que afectaron a un mayor número de personas estuvieron asociados a $\mathrm{ECST}^{8}$.

Por otra parte, en Chile los brotes de ETA han aumentado, desde 581 brotes el año 2005, hasta 1.164 brotes 
notificados en el año 2013, con 7.841 casos $^{9}$. Del total de los brotes notificados en el año 2013, en $10 \%$ de ellos se logró identificar el agente causal, siendo Salmonella spp., el responsable de $54 \%$, seguido por $V$. parahaemolyticus $(27 \%)^{9}$. Hasta el 25 de noviembre de 2014 se notificaron 850 brotes de ETA, con 1,3\% de hospitalizaciones y un fallecido. El 85,2\% de los brotes con agentes identificados (7\%) correspondió a Salmonella spp., seguido lejanamente por $V$. parahaemolyticus $(3,3 \%), E$. coli diarreogénica (3,3\%), Campylobacter spp. (3,3\%), Vibrio spp. (1,6\%), Shigella spp. $(1,6 \%)$ y rotavirus $(1,6 \%)^{10}$. Los alimentos involucrados en los brotes del año 2013 correspondieron en primer lugar a comidas y platos preparados (40\%), seguidos de pescado y productos de la pesca $(32 \%)$ y huevos y ovo-productos $(10 \%)^{9}$.

A pesar de la existencia de diversas tecnologías que son empleadas para disminuir la carga de patógenos bacterianos en alimentos, éstas no son infalibles. En frutas y vegetales, por ejemplo, las dos técnicas más utilizadas para limitar el crecimiento de bacterias, son el lavado con agua y el lavado con soluciones químicas antibacterianas, sin someter el alimento a tratamiento posterior alguno antes de su consumo. Si bien estas medidas son efectivas, el uso indiscriminado de químicos ha estimulado el desarrollo de resistencia bacteriana, disminuyendo por ende su eficacia ${ }^{11,12}$. Por otro lado, en carnes y subproductos cárnicos la medida de control bacteriano más empleada es la aplicación de un tratamiento térmico previo al consumo. Si bien esta es una medida efectiva cuando se aplica en forma apropiada, la incorrecta cocción o el contacto posterior al tratamiento con alimentos crudos contaminados, potencialmente podría re-contaminar ese producto, siendo factible que sea el responsable de una ETA. Es bien sabido que la mayoría de las ETA se producen en el hogar; por lo tanto, continuamente se buscan nuevas formas de control que logren cumplir con los estándares sanitarios exigidos, facilidad de uso, que sean efectivos, seguros, económicos y que tengan un mínimo impacto sobre las propiedades nutricionales y organolépticas de los productos alimenticios ${ }^{11}$.

Una herramienta de creciente interés en la industria alimentaria corresponde al uso de bacteriófagos, también conocidos como fagos, que corresponden a virus cuyo hospedero específico son las bacterias. Si bien fueron descritos por primera vez en 1915 por Frederick Twort y posteriormente, en 1917, por Félix d'Herelle, quien les dio el nombre de bacteriófagos por su capacidad de lisar bacterias, los primeros estudios relativos al uso de estos agentes para reducir patógenos bacterianos en alimentos comenzó aproximadamente en el año $2001^{13,14}$. Son los entes biológicos más abundantes de la tierra, ocupando prácticamente todos los nichos ecológicos donde poseen un rol determinante en el balance de los ecosistemas bacterianos $^{15-17}$. Así, por medio de estimaciones cuantitativas de epifluorescencia, se determinó que cada mililitro de agua de mar contiene millones de estas partículas y, más aún, la abundancia es aún mayor en sedimentos marinos superficiales cercanos a la costa, encontrándose $10^{8}-10^{9}$ virus por $\mathrm{cm}^{318}$. Por extrapolación, la población total de fagos se estima en $10^{8}$ especies y $10^{31}$ partículas en la biosfera, siendo una de las entidades replicantes más abundantes en el mundo ${ }^{19}$. Los bacteriófagos han sido aislados desde una gran variedad de alimentos y procesos asociados, incluyendo la fermentación de pepinos, fermentación de salame, hojas de lechuga, cangrejos refrigerados y congelados, carne de vacuno y de cerdo, ostras, mejillones, setas, tortas, masa de galletas y pan, pollo y pavo crudos $\mathrm{y}$ asados, leche, queso, yogurt y mantequilla ${ }^{20,21}$.

La taxonomía de estos virus se basa en características morfológicas, como forma y tamaño, y moleculares, como las características de sus ácidos nucleicos. La mayoría de los fagos poseen cola, constituyendo el orden Caudovirales, y las tres familias Siphoviridae, Myoviridae y Podoviridae. Los fagos poliédricos, filamentosos y pleomórficos constituyen menos de $4 \%$ de estos virus ${ }^{22}$. Los ácidos nucleicos presentes en estos virus pueden ser ADN o ARN, de hebra simple o doble, siendo en la mayoría ADN de hebra doble ${ }^{23}$.

En base a su ciclo replicativo, los bacteriófagos se clasifican en dos tipos: lisogénicos (o templados) y líticos (o virulentos). Los bacteriófagos del tipo lisogénico inyectan e insertan su ADN en el cromosoma bacteriano donde se replica como parte del genoma del hospedero, pudiendo permanecer en estado de latencia (estado de profago) por períodos prolongados; en este estado, ya sea en forma espontánea o por factores ambientales, pueden ser inducidos a entrar en un ciclo lítico. Su uso no es recomendable ni como agentes terapéuticos ni como bio-controladores en alimentos, pues en algunos casos pueden portar genes que codifiquen para factores de virulencia o de resistencia a antimicrobianos, como es el caso de la Shiga toxina en $E$. coli, toxina eritrogénica de Streptococcus pyogenes, toxina de Corynebacterium diphtheriae y ciertas enterotoxinas de $S$. aureus, factores que además pueden ser transferidos de una bacteria a otra mediante transducción ${ }^{23-25}$.

Por otra parte, el ciclo replicativo de los bacteriófagos líticos (Figura 1) comienza con su unión específica a un receptor en la superficie de la bacteria (cápsula bacteriana, lipopolisacárido, algunas proteínas de superficie y estructuras especializadas tales como flagelos y fimbrias) y posterior inyección de su genoma. Después, el material genético inyectado es replicado mediante la batería enzimática bacteriana, ensamblándose nuevas partículas virales, las que serán finalmente liberadas mediante la lisis de la bacteria hospedera, generándose una nueva progenie viral. Para ser usados en cualquier aplicación, ya sea terapéutica o de bio-control en alimentos, los bacteriófagos 
Figura 1. Esquema general del ciclo lítico de un fago. 1 Adsorción a la superficie bacteriana; 2: Inyección de genoma viral y disrupción del genoma bacteriano; 3: Producción de estructuras virales; 4: Ensamble y formación de progenie viral; y 5: Lisis celular y liberación de viriones. deben ser cuidadosamente caracterizados para elegir sólo aquellos que tengan características exclusivamente líticas, pues eliminan rápidamente a su hospedero, aumentan su progenie rápidamente y su transducción es $\operatorname{rara}^{26}$. Sobre este precepto, Carlton y cols. ${ }^{27}$, secuenciaron y caracterizaron al genoma del bacteriófago P100, bacteriófago específico para Listeria spp., para descartar que alguna de sus proteínas fuesen potencialmente peligrosas para la salud, no encontrando similitud genética alguna con cualquiera de las toxinas o factores involucrados en la virulencia o patogenicidad de L. monocytogenes.

Una de las características más importantes que poseen los fagos es la especificidad por un hospedero en particular. Esta especificidad es generalmente encontrada a nivel de cepa, a nivel de especie, o más raramente a nivel de género ${ }^{28}$. Esto es determinado principalmente por la interacción con los receptores celulares y posteriormente por los sistemas de restricción-modificación bacteriana ${ }^{20}$. Al poseer esta especificidad, los fagos tienen la capacidad de no afectar cultivos bacterianos utilizados en la manufactura de ciertos alimentos y no afectar las propiedades organolépticas que ciertas poblaciones bacterianas otorgan a los alimentos ${ }^{29}$. Junto a esto, ha sido demostrada

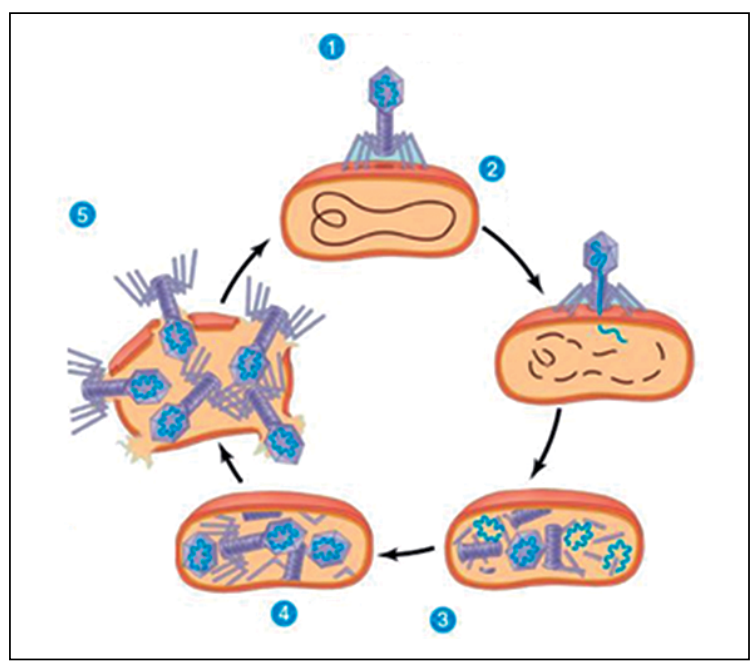

su inocuidad para células eucariotas. Así, Di Giovine y cols. ${ }^{30}$, modificaron genéticamente un bacteriófago para que fuese capaz de reconocer una integrina presente en células de mamífero. Sin embargo, a pesar de esta modificación, los virus no fueron capaces de multiplicarse en el interior de dichas células. Los bacteriófagos son reconocidos por no poseer tropismo intrínseco por células eucariotas ${ }^{22}$. Estas características los convierten en agentes naturales para el control de ciertas bacterias patógenas transmitidas por alimentos.

Inicialmente, los bacteriófagos líticos fueron utilizados como agentes terapéuticos para prevenir o reducir enfermedades bacterianas, tanto en personas como animales (fagoterapia). Sin embargo, desde comienzos del siglo XXI su uso se ha extendido, siendo actualmente utilizados como bio-sanitizantes de equipamientos $\mathrm{y}$ superficies de contacto en la industria alimentaria; como indicadores de contaminación bacteriana en alimentos; como bio-preservantes, para extender la vida útil de productos perecibles y listos para el consumo, y como bio-controladores, utilizados en la cadena de producción alimentaria para descontaminar carcasas y otros productos $\operatorname{crudos}^{20,31}$ (Figura 2).

La presencia de bacteriófagos en los alimentos ha sido ampliamente estudiada como indicadora de patógenos bacterianos, ya que señalan que el agente hospedero está presente, o bien lo estuvo pero fue inactivado durante el procesamiento. Por lo tanto, la presencia de colifagos, cuyo hospedero es $E$. coli, podría ser indeseable en algunos alimentos, pero no inesperada en otros (como por ejemplo la carne cruda). Ya que los bacteriófagos están comúnmente asociados a la presencia de sus hospederos específicos y, por lo tanto, son parte de la microbiota normal, se ha propuesto su uso como indicadores de la calidad higiénica de los alimentos ${ }^{20}$.

Como cualquier otra herramienta, la utilización de bacteriófagos como agentes bio-controladores en alimentos presenta diversas ventajas y desventajas. Dentro de las ventajas se describen:

- Capacidad exclusivamente bactericida ${ }^{32}$.

- Crecimiento exponencial de las partículas virales. Los fagos durante el proceso de muerte bacteriana son

Figura 2. Posibilidades de uso de bacteriófagos virulentos en la cadena productiva alimentaria.

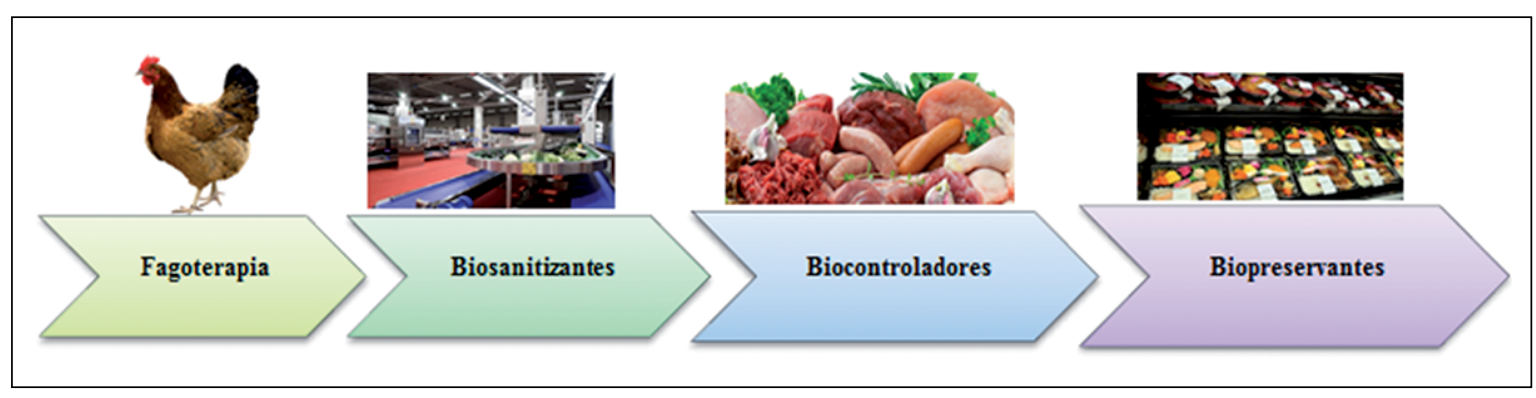


capaces de aumentar su número en presencia de su bacteria blanco ${ }^{32}$.

- Efectos mínimos sobre la microbiota normal presente en los alimentos. Debido a su estrecha especificidad de hospedero ${ }^{32}$. También, se debe considerar la inocuidad de los medios líquidos donde son vehiculizados ${ }^{33-35}$.

- Reducido potencial para inducir resistencia bacteriana. Las bacterias pueden generar mutaciones que expresen resistencia frente a los fagos líticos ${ }^{36}$; sin embargo, se utiliza la estrategia de administrar mezclas de fagos, con lo cual se minimiza la probabilidad de que la bacteria desarrolle resistencia a todos los fagos que constituyen la mezcla ${ }^{32}$.

- Alta especificidad frente a células bacterianas. Algunos estudios de toxicidad realizados con fagos en animales de experimentación, como pollos y ratones, no han inducido efectos tóxicos ni reacciones adversas en los animales ${ }^{37,38}$. Bruttin y Brüssow ${ }^{39}$, administraron fagos T4 contra E. coli, a 15 personas voluntarias, en bajas y altas dosis $\left(10^{3}\right.$ y $10^{5}$ unidades formadoras de placas (ufp)/mL). Los voluntarios recibieron los fagos en $150 \mathrm{~mL}$ de agua mineral tres veces al día por dos días consecutivos, seguidos de cinco días consecutivos sin recibir tratamiento con fagos. Este procedimiento fue repetido por tres semanas. Se realizó un examen clínico el día 0 y el día 30 del estudio, y además, los voluntarios recibieron un cuestionario en el cual podían informar cualquier tipo de eventos adversos. Se presentaron sólo cinco eventos adversos leves, cuatro de ellos con síntomas intestinales (dolor estomacal, náuseas, aumento de peristaltismo) y un voluntario presentó faringodinia. Ninguno de estos casos necesitó tratamiento. La inocuidad de los bacteriófagos para el hombre y animales, se ha reconocido toda vez que se aprobó su uso como aditivo en alimentos de consumo humano y su uso directamente en animales ${ }^{40}$.

- Bajo impacto ambiental. Debido a su composición química y a su estrecho rango de hospederos, las partículas virales eliminadas al medio posterior a su utilización, en el peor de los casos, sólo tendrán un impacto en un pequeño grupo de bacterias ambientales ${ }^{32}$.

- Bajo costo. Mientras que el valor de crecer al virus en su hospedero varía dependiendo del tipo bacteriano, el costo de su purificación parece ir disminuyendo a medida que las tecnologías mejoran ${ }^{32}$.

Por otra parte, dentro de las principales preocupaciones y desventajas del uso de fagos se describen:

- Selección rigurosa. Basada en corroborar que los fagos utilizados sean estrictamente líticos, estables bajo ciertas condiciones físico-químicas y temperaturas de almacenamiento. Estos virus deben ser sometidos a estudios de eficacia e inocuidad e, idealmente, ser completamente secuenciados para confirmar la au- sencia de genes no deseados como los de toxinas. La caracterización de los fagos puede incluir morfología de los viriones, perfiles proteicos, y caracterización genotípica, aunque los costos asociados a esta exhaustiva caracterización pueden ser restrictivos ${ }^{32}$.

- Reducido rango de hospederos. Esta característica dificulta la opción de utilizar un mismo fago para disminuir la contaminación causada por bacterias de especies diferentes, o en algunos casos incluso de serotipos diferentes ${ }^{32}$.

- Necesidad de una concentración bacteriana alta. Esto constituye un requerimiento obligatorio para que los fagos puedan replicarse y lisar las bacterias, por lo que su administración se limitaría casi exclusivamente a alimentos considerados de riesgo. La falta de bacterias puede llevar a una rápida inactivación, lo que puede resultar en la necesidad de administrar posteriormente mayores concentraciones ${ }^{41}$.

- Altas multiplicidades de infección (MOI por sus siglas en inglés). Diversos estudios internacionales han demostrado que mientras más alta es la MOI (relación fago: bacteria) utilizada, mayores son las reducciones obtenidas $^{14,42-45}$. El hecho de obtener elevados títulos de fagos puede representar una limitante económica y tecnológica, ya que se debe contar con equipos sofisticados para la concentración y purificación viral.

- Existencia de barreras físico-químicas que disminuyen la interacción bacteria-fago. Las características físicas del alimento constituyen un factor importante que influye en la acción bio-controladora de los fagos, siendo reportado un mejor efecto de estos en alimentos líquidos que en sólidos ${ }^{46}$. Otro elemento que puede interferir con su acción es el pH, ya que se conoce que algunos bacteriófagos no pueden persistir si se exponen a pH ácido. Sin embargo, la sensibilidad a bajos valores de $\mathrm{pH}$ dependerá del tipo de bacteriófago ${ }^{22}$.

- Problemas en la percepción de los consumidores. Los consumidores pueden mostrarse reacios a consumir alimentos que fueron tratados en diferentes momentos de su producción con bacteriófagos ${ }^{47}$.

\section{Bio-control de patógenos alimentarios a través de bacteriófagos}

El uso de fagos para controlar patógenos alimentarios es relativamente reciente en comparación a su uso en aplicaciones terapéuticas y diagnósticas. El bio-control fue investigado inicialmente en productos frescos, seguido de lácteos y cárneos; centrándose en la aplicación de dichos virus durante el procesamiento de estos productos contra diversos patógenos causantes de enfermedades transmitidas por los alimentos (ETAs), como L. monocytogenes $^{35,46,48-50}$ y E. coli ${ }^{51-53}$. Los resultados obtenidos de estas experiencias fueron bastante promisorios, lo que ha llevado al desarrollo de diversos productos comerciales 
Tabla 1. Productos en base a bacteriófagos disponibles comercialmente para ser usados directamente en alimentos

\begin{tabular}{|c|c|c|c|c|}
\hline Producto & Compañía & n de bacteriófagos & Bacteria blanco & Alimentos \\
\hline EcoShield ${ }^{\top M}$ & Intralytix & Combinación de 3 fagos & Escherichia coli 0157:H7 & Alimentos de riesgo, incluyendo carne de vacuno \\
\hline ListShield ${ }^{\mathrm{TM}}$ & Intralytix & Combinación de 6 fagos & Listeria monocytogenes & $\begin{array}{l}\text { Alimentos de riesgo incluyendo salmón ahumado y } \\
\text { productos cárneos y avícolas listos para su consumo }\end{array}$ \\
\hline Listex ${ }^{\mathrm{TM} P 100}$ & Micreos & Sólo el fago P100 & Listeria monocytogenes & $\begin{array}{l}\text { Alimentos de riesgo incluyendo quesos, pescados } \\
\text { y carnes }\end{array}$ \\
\hline Salmofresh ${ }^{\mathrm{TM}}$ & Intralytix & Combinación de 6 fagos & Salmonella enterica & $\begin{array}{l}\text { Carnes rojas, carne de pollo, pescados, frutas y } \\
\text { vegetales }\end{array}$ \\
\hline Agriphage $\mathrm{T}^{\top \mathrm{M}}$ & Omnylytics & Sólo un fago & $\begin{array}{l}\text { Xanthomonas campestris pv. vesicatoria y } \\
\text { Pseudomonas syringae pv. tomato }\end{array}$ & Plantas de tomates y pimentones \\
\hline Salmonelex ${ }^{\top M}$ & Micreos & Combinación de 2 fagos (Fola y S16) & S. enterica & Alimentos de riesgo, incluyendo productos avícolas \\
\hline
\end{tabular}

en base a bacteriófagos, algunos de los cuales ya han obtenido las aprobaciones regulatorias necesarias para su uso en la industria alimentaria (Tabla 1). Así, durante el año 2006 el preparado comercial LMP-102 ${ }^{\mathrm{TM}}$ de la empresa Intralytix, consistente en una mezcla de seis fagos con acción sobre L. monocytogenes, fue aprobada por la Food and Drug Administration (FDA, USA), para su uso en productos cárnicos y avícolas listos para el consumo. Otro producto con acción sobre L. monocytogenes, aprobado por la FDA es LISTEX ${ }^{\mathrm{TM}}$, de la empresa Micreos Food Safety, que amplió su uso, durante el año 2007, a todos los alimentos de riesgo de contaminación con esta bacteria, y también adquiriendo la categoría de producto GRAS (generalmente reconocido como seguro, por sus siglas en inglés $)^{54,55}$. OmniLytics Inc. recibió la aprobación de la FDA para su producto a base de bacteriófagos contra E. coli y Salmonella para ser utilizado en animales vivos, antes de su sacrificio, ya sea en base a ducha (ganado) o nebulización (aves de corral) ${ }^{56}$. Si bien, hay estudios que respaldan la efectividad de estos productos, su acción depende de la conjunción de diversos factores que podrían limitar o aumentar su eficacia. Es de vital importancia por lo tanto, conocer estos factores y tomar las medidas necesarias para lograr resultados óptimos.

En Chile, nuestro equipo de trabajo junto al apoyo de CONICYT, mantiene una línea de investigación sobre la actividad terapéutica y bio-controladora de bacteriófagos contra Salmonella Enteritidis, principal patógeno involucrado en brotes de ETA. Puntualmente, en el área de bio-control, hemos registrado reducciones significativas en el recuento de este patógeno en diversas matrices alimentarias de origen animal, consideradas de riesgo para la salud pública. Así, Galarce y cols. ${ }^{57}$, evaluaron la aplicación de una mezcla de cinco bacteriófagos líticos activos contra $S$. Enteritidis en carne de salmón fresca y carne de salmón ahumada. Estos alimentos fueron contaminados experimentalmente luego, tratados con la mezcla de bacteriófagos e incubados por 10 días a temperatura de refrigeración $\left(4^{\circ} \mathrm{C}\right)$ y ambiente $\left(18^{\circ} \mathrm{C}\right)$. La aplicación de fagos provocó reducciones significativas $(\mathrm{p} \leq 0,0033)$ en el recuento de $S$. Enteritidis en salmón fresco en los días 3 , 6 y 10 de incubación a $4^{\circ} \mathrm{C}$ (entre 2,82 a $3,12 \log _{10}$ ufc/g) y a $18^{\circ} \mathrm{C}$ (entre 0,75 a $3,19 \log _{10} u f c / g$ ); mientras que, en salmón ahumado las reducciones $(\mathrm{p} \leq 0,0001)$ fueron menores e independientes de la temperatura $\left(<\mathrm{a} 2,00 \log _{10}\right.$ $\mathrm{ufc} / \mathrm{g}$ ). Utilizando el mismo protocolo y la misma mezcla de bacteriófagos, Jorquera y cols..$^{58}$, también obtuvieron reducciones significativas de $S$. Enteritidis $(\mathrm{p} \leq 0,05)$ en carnes frescas de pollo, pavo y vacuno. Dependiendo de la temperatura y tipo de alimento, las unidades de reducción fluctuaron entre 1,67 y $3,92 \log _{10} u f c / g$. En la carne de vacuno y de pavo, en particular, la mezcla de bacteriófagos redujo los recuentos de $S$. Enteritidis por debajo del límite de detección $\left(<10^{1} \mathrm{ufc} / \mathrm{g}\right)$. En queso maduro de cabra, los bacteriófagos lograron disminuir los recuentos de $S$. Enteritidis ( $\mathrm{p} \leq 0,05)$ pero con valores menores que en carnes frescas $\left(1,42 \log _{10} \mathrm{ufc} / \mathrm{g}\right)$ y sólo hasta el día 3 de incubación, en ambas temperaturas. Continuando con la línea, Yévenes ${ }^{59}$ evaluó la efectividad en mayonesa casera experimentalmente contaminada con $S$. Enteritidis e incubada por $72 \mathrm{~h}$ a temperatura ambiente $\mathrm{y}$ de refrigeración. Al igual que en las experiencias anteriores, la mezcla de bacteriófagos redujo $(\mathrm{p}<0,0001)$ el recuento del patógeno, disminuyendo en $2,97 \log _{10} \mathrm{ufc} / \mathrm{g}$ y $2,82 \log _{10}$ ufc/g a las 24 y $72 \mathrm{~h}$ de incubación a $6^{\circ} \mathrm{C}$, respectivamente; mientras que a $21^{\circ} \mathrm{C}$, la disminución fue de $2,14 \log _{10}$ ufc/g y de $3,0 \log _{10} \mathrm{ufc} / \mathrm{g}$ a las 24 y 72 $\mathrm{h}$ de incubación, respectivamente. Nuestros resultados demuestran el potencial bio-controlador de la mezcla de bacteriófagos sobre $S$. Enteritidis en diversos alimentos, frescos y procesados, aunque mayores estudios son necesarios para mejorar los niveles de reducción y para determinar la ausencia de genes nocivos en el genoma de los bacteriófagos seleccionados. 
Factores que afectan la eficiencia de los bacteriófagos como agentes bio-controladores en alimentos

A pesar de poseer diversas ventajas comparativas, éstas son susceptibles a varios factores. Dentro de los factores que pueden influir en la efectividad bactericida de los bacteriófagos en alimentos se encuentra:

\section{Factores propios del alimento}

\section{- Matriz alimentaria}

Este es, sin duda, un factor crucial ya que la interacción de los diversos componentes, tanto nutritivos como no nutritivos, le confiere las características físico-químicas a cada uno de los alimentos, las cuales pueden generar un ambiente apto u hostil para la acción del bacteriófago. Se debe tener en cuenta que, para ejercer su efecto, la concentración del bacteriófago debe ser lo suficientemente alta para permitir el contacto con la célula hospedera. En alimentos líquidos, esto no significa un mayor problema, pues las partículas virales difunden libremente en él; sin embargo, en alimentos sólidos dependerá de la capacidad del alimento para adsorber la suspensión fágica y que ésta no se diluya ${ }^{46}$. Una solución que evitaría este problema sería la inmovilización de fagos. Para ello se ha aprovechado la diferencia de cargas en las estructuras que conforman a los fagos, la que permite fijarlos a través de sus cabezas en una matriz cargada positivamente, dejando así las fibras de la cola libres para capturar a su bacteria blanco y producir su infección. Esto aseguraría que los fagos sean aplicados y mantenidos cerca de la superficie tratada, impidiendo así una excesiva pérdida de partículas virales. En este contexto, Anany y cols. ${ }^{60}$, midieron la efectividad de bacteriófagos inmovilizados electroestáticamente en membranas de celulosa cargadas positivamente, aplicadas sobre alimentos listos para el consumo y carne cruda contaminadas con L. monocytogenes y E. coli $\mathrm{O} 157: \mathrm{H} 7$, respectivamente. En esta investigación se evidenció que el uso de fagos inmovilizados, aún en diferentes temperaturas de almacenamiento $\left(4,10 \mathrm{o} 25^{\circ} \mathrm{C}\right)$ y condiciones de envasado (aeróbico, atmósfera modificada y vacío), permitió obtener reducciones hasta $1 \log$ mayores que las obtenidas utilizando fagos no inmovilizados.

Sumado a esto, la matriz no sólo puede limitar la difusión de los virus, sino también influir en su capacidad infectante. De esta manera, Guenther y cols. ${ }^{46}$, analizaron la efectividad de un bacteriófago contra $L$. monocytogenes en alimentos listos para el consumo, como hot dogs, leche chocolatada, repollo y lechuga, almacenados a $6^{\circ} \mathrm{C}$ por seis días. Una de las observaciones que realizaron en esta experiencia fue que, a diferencia de otros productos evaluados dentro de este estudio, el tiempo de almacenamiento influyó en la estabilidad del fago en los productos de origen vegetal, donde el número de partículas infectantes disminuyó hasta $2 \log$ en dos o tres días, acompañado de un aumento en la concentración bacteriana. Según los autores, esto podría deberse a que compuestos vegetales, como ácidos orgánicos y taninos, inactivarían a los bacteriófagos.

\section{- $\mathrm{pH}$}

Es bien conocido que las bacterias, en su mayoría, no se desarrollan en ambientes extremadamente ácidos; sucediendo lo mismo con los bacteriófagos. Distintos estudios han indicado que ellos son usualmente estables a valores de $\mathrm{pH}$ entre 5 y 8 , extendiéndose este rango entre 4 y 10 cuando la temperatura es baja ${ }^{20}$. Una de las primeras investigaciones que evidenció la importancia del $\mathrm{pH}$ en la efectividad bio-controladora de los bacteriófagos fue la de Leverentz y cols. ${ }^{13}$. En este estudio se utilizó una mezcla de cuatro bacteriófagos aplicados en láminas de manzana y melón experimentalmente contaminados con $S$. Enteritidis. Los resultados indicaron que en las láminas de melón se logró una reducción entre 2,5 y 3,5 unidades logarítmicas, mientras que el grupo control aumentó sus recuentos de $S$. Enteritidis en hasta 5 unidades logarítmicas. En contraste, en cortes de manzana la mezcla de bacteriófagos no redujo el recuento bacteriano, siendo esto atribuido por los autores a la posible incapacidad de los bacteriófagos utilizados para sobrevivir en el ambiente ácido ( $\mathrm{pH} 4,2)$ que esta fruta posee. En un estudio posterior realizado por estos mismos autores para controlar $L$. monocytogenes utilizando una combinación bacteriófagonisina (bacteriocina producida por bacterias ácido lácticas y utilizada como preservante) en estos mismos alimentos, arrojó resultados similares, atribuyéndose nuevamente al $\mathrm{pH}$ como el responsable de la sobrevida del fago ${ }^{61}$. Frente a estas situaciones, una probable estrategia para obtener mayores reducciones sea el uso de una concentración más alta de virus para así, poder contrarrestar la acidez del alimento o bien utilizar bacteriófagos que sean más resistentes a esta condición.

\section{- Temperatura}

Un punto importante de considerar al usar los bacteriófagos como bio-controladores es la temperatura a la cual se almacenan los alimentos. Sharma y cols. ${ }^{62}$, evaluaron la efectividad del fago P100, al ser aplicado sobre cortes frescos de melón y lechuga contra L. monocytogenes, evidenciándose una mayor efectividad de los bacteriófagos cuando los productos se almacenaron a temperatura de refrigeración $\left(4^{\circ} \mathrm{C}\right)$ que a $20^{\circ} \mathrm{C}$, posiblemente debido a la capacidad de los fagos para resistir bajas temperaturas.

Recientemente, Bigot y cols. ${ }^{63}$, trabajaron con un bacteriófago de características similares al bacteriófago A511. Éste fue aplicado sobre la superficie de un rollo de pechuga de pavo listo para el consumo, envasado al 
vacío y mantenido por 21 días a $30^{\circ} \mathrm{C}$ o $5^{\circ} \mathrm{C}$. A $30^{\circ} \mathrm{C}$ produjo una rápida reducción de L. monocytogenes, pudiendo mantener esta reducción sólo hasta las siete horas post aplicación. A $5^{\circ} \mathrm{C}$ se observó una reducción significativa, que se mantuvo hasta 21 días post administración del fago.

También se ha observado que la temperatura a la cual se procesa el alimento ejerce un efecto variable sobre los bacteriófagos, demostrando ser más termo-tolerantes que las bacterias, pudiendo incluso sobrevivir a tratamientos aplicados rutinariamente para algunos alimentos, como por ejemplo la pasteurización ${ }^{20}$. Este efecto puede ser directo sobre la partícula viral, o bien indirecto al modificar el ambiente en el cual el fago tendrá que permanecer.

En un estudio realizado por Modi y cols. ${ }^{14}$, se evaluaron los efectos del bacteriófago SJ2 en la supervivencia de $S$. Enteritidis durante la fabricación y maduración de queso Cheddar, utilizando tanto leche cruda como pasteurizada. Los virus fueron aplicados directamente en ambos tipos de leche antes de fabricar el producto. Los quesos fueron envasados al vacío y mantenidos por 99 días a $8^{\circ} \mathrm{C}$. A las 24 $\mathrm{h}$ de aplicado el fago, no hubo una diferencia significativa en las reducciones de $S$. Enteritidis según el tipo de leche utilizada en la fabricación del queso. Pasado los 90 días de almacenamiento, no se encontró presencia de la bacteria en quesos elaborados en base a leche pasteurizada, mientras que en los elaborados en base a leche cruda se observó un recuento de aproximadamente 50 ufc/g a los 99 días de maduración. Se concluyó entonces, que los fagos tendrían una mayor actividad cuando se aplican sobre leche pasteurizada, pues al desnaturalizarse las proteínas, se reduce la firmeza del coágulo, habiendo menos drenaje de suero y por ende, menos pérdida de fagos. Otra hipótesis que explica esta diferencia, es la presencia de inhibidores de la actividad fágica sensibles al calor.

Kim y cols. ${ }^{64}$, utilizaron dos fagos (ESP 1-3 y ESP 732-1) como herramienta para controlar Cronobacter sakazakii en leche infantil reconstituida a 12,24 y $37^{\circ} \mathrm{C}$. Los resultados arrojaron que a $24^{\circ} \mathrm{C}$ ambos bacteriófagos lograron eliminar completamente la bacteria cuando fueron utilizados en una concentración entre $10^{8}$ y $10^{9} \mathrm{ufp} /$ $\mathrm{mL}$, demostrando con ello que la temperatura parece ser un factor determinante para la eficiencia de la infección por fagos y la lisis bacteriana posterior.

\section{Factores propios del bacteriófago}

\section{- Multiplicidad de infección}

La MOI es un término frecuentemente usado en virología y se refiere al número de viriones que se agregan por célula (en este caso, por bacteria), durante la infección. Se han realizado una variedad de estudios donde se han utilizado distintas MOI, indicando que a mayor MOI se genera una mayor lisis bacteriana. Goode y cols. ${ }^{65}$, y Atterbury y cols. ${ }^{66}$, estudiaron la habilidad de bacterió- fagos líticos para reducir los recuentos de $S$. Enteritidis y Campylobacter jejuni, respectivamente, en secciones de piel de pollo contaminadas experimentalmente. En ambos casos, el uso de una MOI superior a $10^{2}$, provocó reducciones de hasta 2 unidades logarítmicas en $48 \mathrm{~h}$, llegando a no detectar la bacteria cuando se utilizaron MOI de $10^{5}$.

Posteriormente, Higgins y cols. ${ }^{43}$, determinaron la efectividad del bacteriófago PHL4 como bio-controlador de $S$. Enteritidis, tanto con el agua de lavado de carcasas, como directamente en carcasas de pollos y pavos, utilizando dos MOI diferentes: $10^{6}$ y $10^{10}$. En todos los experimentos, al utilizar la MOI mayor se lograron reducciones mayores a las obtenidas con la menor concentración viral; es así como utilizando un inóculo bacteriano de $10^{1} \mathrm{ufc} / \mathrm{mL}$, observaron una reducción en $90 \%$ de las bacterias en las muestras tratadas con la MOI $10^{10}$, mientras que la reducción en las muestras que recibieron el bacteriófago en MOI $10^{6}$ sólo fue de $30 \%$.

En el año 2008, Bigwood y cols. ${ }^{45}$, evaluaron el uso de bacteriófagos para controlar $S$. Typhimurium en carnes crudas y cocidas, comprobando que las mayores diferencias en los recuentos entre grupo experimental y control se lograron cuando existió una alta concentración bacteriana y una alta MOI $\left(10^{4}\right)$, con aproximadamente disminuciones del recuento de $4,8 \log _{10}$ en carne cocida. En la misma matriz, pero usando baja MOI $\left(10^{1}\right)$ con elevada concentración bacteriana, existió una reducción no mayor a 2,6 $\log _{10}$.

Pese a lo anterior, Whichard y cols. ${ }^{67}$, demostraron que no siempre se necesita una alta MOI para obtener buenos resultados. Al aplicar el bacteriófago Felix O1 y una variante de éste en salchichas de pollo previamente contaminadas con $S$. Typhimurium DT104 en una MOI de $10^{1}$, se logró una reducción de aproximadamente $2 \log _{10}$ en relación al grupo control. Esta actividad no aumentó al elevar la MOI a $10^{5}$. Sin embargo, cabe destacar que el crecimiento bacteriano continuó. Esto pudo deberse a la presencia de sub-poblaciones bacterianas resistentes a estos fagos.

Guenther y cols. ${ }^{46}$, evaluaron el rol bio-controlador del fago A511 en variados alimentos contaminados con L. monocytogenes $\left(1 \times 10^{3} \mathrm{ufc} / \mathrm{g}\right)$ los cuales fueron almacenados a $6^{\circ} \mathrm{C}$ por seis días. En hot dogs, al utilizar una MOI de $10^{8}$ se logró una eliminación total del patógeno, mientras que al utilizar MOI de $10^{7}$ y $10^{6}$ se obtuvieron menores reducciones $(2,7 \log \mathrm{ufc} / \mathrm{g}$ y $2,2 \mathrm{ufc} / \mathrm{g}$, respectivamente). La misma situación se evidenció en leche chocolatada, donde al utilizar una MOI de $10^{8}$ se logró la eliminación de la bacteria en esa matriz, mientras que al utilizar MOI de $10^{7}$ y $10^{6}$ las reducciones fueron de $4,4 \log \mathrm{ufc} / \mathrm{g}$ y $1 \log \mathrm{ufc} / \mathrm{g}$, respectivamente. Similares resultados obtuvieron en quesos tipo Camembert y tipo Limburger $^{68}$. 


\section{Otros factores}

- Fagoresistencia

Se han descrito bacterias que exhiben resistencia a los bacteriófagos líticos debida a fenómenos mutaciona$\operatorname{les}^{36}$. Al respecto, Skurnik y Strauch ${ }^{23}$ indicaron que en una población bacteriana de $10^{6}-10^{8} \mathrm{ufc}$, existe una alta posibilidad de encontrar una bacteria fago-resistente con algún receptor mutado, que no puede ser reconocido por el virus. Este fenotipo de fago-resistencia puede originarse por diversos mecanismos, incluyendo el bloqueo de la adsorción viral (bloqueo o pérdida de receptores), producción de matriz extracelular o inhibidores competitivos ${ }^{69,70}$, bloqueo de la inyección del genoma viral dentro de la célula, mecanismos de exclusión de superinfección ${ }^{59,70,71}$, sistemas de restricción-modificación mediado por enzimas que degradan el ácido nucleico viral (CRISPR-Cas) ${ }^{72-75}$, y sistemas abortivos de la infección (sistema Abi) ${ }^{70,73}$.

In vitro los fenómenos de resistencia bacteriana a los bacteriófagos pueden ser tan rápidos como horas o días. Sin embrago, aún no está claro si el desarrollo de la resistencia in vitro es relevante en condiciones in vivo.

Una de las estrategias utilizadas para aumentar la efectividad, considerando este fenómeno, es aplicar mezclas de distintos fagos, en incluso, el uso de esquemas rotatorios. Es así, que la mayoría de las investigaciones enfocadas en el uso de estos virus en alimentos utiliza la combinación de dos o más bacteriófagos ${ }^{76-78}$. Lo anterior ha llevado a que la mayoría de los productos comerciales disponibles actualmente en el mercado sigan esta tendencia (Tabla 1$)^{40}$.

- Combinación con otras medidas de control

Si bien los fagos son una buena alternativa de biocontrol, no logran por lo general una eliminación completa del patógeno, por lo que siempre es recomendable que sean aplicados en forma conjunta a otras medidas para aumentar la eficiencia en la reducción bacteriana. Una de estas medidas, es el uso combinado de fagos con nisina. Leverentz y cols. ${ }^{52}$, utilizaron esta combinación sobre cortes de melón y manzana experimentalmente contaminados con L. monocytogenes. El uso de fagos, solos o en combinación con nisina, resultaron ser efectivos sólo en los cortes de melón, con rangos de reducción entre 2 y 4,6 unidades logarítmicas al aplicar sólo fagos y por sobre 5,7 unidades logarítmicas al usarlo en combinación con nisina. Estos resultados favorables no ocurrieron en los cortes de manzana, debido al $\mathrm{pH}$ ácido de esta fruta que afectó la sobrevida del fago. También se ha estudiado la combinación de fagos y nisina en el bio-control de $S$. aureus en leche pasteurizada, demostrando que al actuar juntos producen una reducción de al menos 1 log mayor que aquella obtenida con estos agentes por separado ${ }^{79}$.

Otra herramienta complementaria es el uso de cultivos protectores. Holck y Berg ${ }^{80}$, analizaron la aplicación de la mezcla de fago P100 junto a un cultivo protector de Lactobacillus sakei $\mathrm{TH} 1$, para controlar el crecimiento de L. monocytogenes en láminas de jamón cocido al vacío almacenado a $10^{\circ} \mathrm{C}$ hasta por 28 días. Los resultados indicaron que al aplicar sólo P100, se produjo una rápida reducción inicial de esta bacteria, para luego alcanzar una concentración similar al grupo control. En cambio, cuando se aplicó la combinación de agentes, se produjo la misma reducción inicial, pero posteriormente se alcanzó una reducción de 2 unidades logarítmicas por sobre lo alcanzado al aplicar sólo el fago P100.

\section{Consideraciones de salud pública}

Aun cuando se ha demostrado que los bacteriófagos líticos no exhiben efectos dañinos sobre las personas y los animales ${ }^{81}$, son necesarias pruebas de seguridad y eficacia. Estas pruebas idealmente deben considerar estudios de secuenciación para confirmar que los fagos utilizados son exclusivamente virulentos (no lisogénicos), y que además se asegure que su genoma esté libre de genes que codifiquen para factores de virulencia y elementos genéti$\cos$ que faciliten la transferencia génica entre bacterias ${ }^{82}$.

\section{Conclusiones}

Desde el aislamiento y caracterización de los bacteriófagos, no es extraño que su uso se dirigiera hacia la terapia en personas. Sin embargo, la aparición de los primeros antimicrobianos de amplio espectro originó el fin de la fagoterapia. El uso y abuso sistemático de estos fármacos desencadenaron la aparición de bacterias resistentes a los antimicrobianos, situación que actualmente es considerada prioritaria para la Organización Mundial de la Salud (OMS), la Organización Mundial de Sanidad Animal (OIE) y Organización de las Naciones Unidas para la Alimentación y la Agricultura (FAO). De esta forma y, bajo el concepto de "Una Salud", es imperativo que los esfuerzos se dirijan hacia la investigación de elementos alternativos a los antimicrobianos para uso humano, veterinario, agrícola y ambiental. En este contexto, renace la antigua idea de utilizar los bacteriófagos, ahora con una visión más amplia que abarca además de la terapéutica, el control de patógenos en los alimentos.

Trabajar para lograr la inocuidad de alimentos es una tarea importante para el sector productor y comercializador de nuestro país ya que asegura la disponibilidad de alimentos inocuos para la población y además, nos permite cumplir con los exigentes estándares del comercio internacional, favoreciendo con ello el desarrollo exportador. Siendo la visión global de la inocuidad alimentaria el control de los patógenos en toda la cadena alimentaria, desde la "granja a la mesa", la aplicación de bacteriófagos directamente en el alimento debe ser considerada en nues- 
tro país como un aporte innovador que nos pone a la altura de otras naciones desarrolladas que han aceptado su uso.

En vista de los antecedentes expuestos en este artículo, se hace manifiesto que los bacteriófagos resultan ser una eficaz forma de bio-control de patógenos alimentarios, dependiendo fuertemente su efectividad de una serie de factores que deben ser analizados experimentalmente antes de su potencial comercialización. Dentro de los factores a considerar, se encuentra no sólo la concentración viral, sino también la concentración de la bacteria blanco, las propiedades físico-químicas de la matriz alimentaria y las características de estabilidad y tolerancia de los fagos a diversas condiciones ambientales. En nuestra experiencia, el aislamiento, caracterización, amplificación y aplicación de bacteriófagos en los alimentos constituyó un proceso rápido, eficiente y sin mayores restricciones económicas ni tecnológicas. Sumado a esto, otro factor fundamental que no puede dejarse de lado, es la percepción de los consumidores frente al hecho de consumir virus en sus alimentos cotidianos. Este hecho debe ser abordado tanto por la academia como por la industria en su conjunto, para así poder utilizar de manera efectiva esta promisoria herramienta con el consecuente beneficio para la salud pública, para el sector productor y para el comercio exterior.

\section{Resumen}

Las enfermedades transmitidas por alimentos son un creciente problema de salud pública, donde los agentes patógenos bacterianos juegan un rol trascendental. La industria alimentaria ha implementado diversas medidas de control para enfrentar esta situación, utilizando en la última década algunas herramientas biotecnológicas, como es la aplicación de bacteriófagos directamente en los alimentos. Sus propiedades exclusivamente bactericidas e inocuas para el hombre y los animales han sido descritas ampliamente en la literatura científica, existiendo a la fecha algunos productos comerciales disponibles en el mercado internacional. A pesar de esto, diversos son los factores que pueden influir en su efectividad bio-controladora en alimentos, por lo que conocer dichos factores resulta fundamental antes de considerar su aplicación. De esta manera, se logrará obtener la máxima actividad reductora de la carga bacteriana, generando así un alimento más seguro. Esta revisión aborda ciertos factores a considerar para el uso de bacteriófagos como agentes bio-controladores de patógenos alimentarios, incluyendo antecedentes históricos, taxonomía y descripción biológica de bacteriófagos, así como ventajas, desventajas y consideraciones de su aplicación en alimentos.

\section{Referencias bibliográficas}

1.- FAO/OMS. Organización de las Naciones Unidas para la Agricultura y la Alimentación (FAO) y Organización Mundial de la Salud (OMS). 1998. Codex Alimentarius: Requisitos Generales (Higiene de los Alimentos). Suplemento 1 Volumen 1B. Segunda edición. $58 \mathrm{pp}$.

2.- $\quad$ Soto A, Oviedo P. Capítulo 2: Inocuidad de los Alimentos de Origen Pecuario en Chile: Realidad y Perspectivas. Agencia de Cooperación Técnica IICA en Chile. Niño de Zepeda A, Echavarri V, Godoy P. De Recursos Productivos a Alimentos: Estrategias de Calidad, primera edición, 1999, p. 13-26.

3.- Buzby J, Roberts T. The economics of enteric infections: human foodborne disease costs. Gastroenterology 2009; 136: 1851-62.

4.- Alerte V, Cortés S, Díaz J, Vollaire J, Espinoza E, Solari V, et al. Brotes de enfermedades transmitidas por alimentos y agua en la Región Metropolitana, Chile (2005-2010). Rev Chilena Infectol 2012; 29: 26-31.

5.- Scallan E, Hoekstra R, Angulo F, Tauxe R, Widdowson M A, Roy S, et al. Foodborne illness acquired in the United States-major pathogens. Emerg Infect Dis 2011; 17: 7-15.

6.- Barton B, Jones T, Vugia D, Long C, Marcus R, Smith K, et al. Deaths associated with bacterial pathogens transmitted commonly through food: foodborne diseases active surveillance network (FoodNet), 1996-2005. J Infect Dis 2011; 204: 263-7.

7.- CDC. Centers for Disease Control and Prevention. Surveillance for foodborne disease outbreaks United States, 2012: annual report. 2014. <http://www.cdc.gov/foodsafety/pdfs/ foodborne-disease-outbreaks-annual-report2012-508c.pdf $>$ [consultado el 13 de noviembre de 2014].

8.- EFSA. European Food Safety Authority. The European Union summary report on trends and sources of zoonoses, zoonotic agents and foodborne outbreaks in 2011. EFSA Journal 2013; 11: $3129,250 \mathrm{pp}$.

9.- MINSAL. Ministerio de Salud Chile, Departamento de Epidemiología. Informe de situación: brotes enfermedades transmitidas por los alimentos (ETA) Chile, semana epidemiológica (SE) 1 a 52 año 2013. 2014 b. $<$ http://epi.minsal.cl/epi/html/bolets/reportes/ Entericas/ETA_2013.pdf $>$ [consultado el $30 \mathrm{de}$ noviembre de 2014].

10.- MINSAL. Ministerio de Salud Chile, Departamento de Epidemiología. Informe Enfermedades entéricas semana 47 2014a. $<$ http://epi.minsal.cl/epi/html/bolets/reportes/ Entericas/Informe_Entericas_SE472014. pdf\#page $=4>$ [consultado el 30 de noviembre de 2014].
11.- Abuladze T, Li M, Menetrez M, Dean T, Senecal A, Sulakvelidze A. Bacteriophages reduce experimental contamination of hard surfaces, tomato, spinach, broccoli and ground beef by Escherichia coli O157:H7. Appl Environ Microbiol 2008; 74: 6230-8.

12.- O'Flaherty S, Ross P, Coffey A. Bacteriophage and their lysins for elimination of infectious bacteria. FEMS Microbiol Rev 2009; 33: 801-9.

13.- Leverentz B, Conway W S, Alavidze Z, Janisiewicz W J, Fuchs Y, Camp M J, et al. Examination of bacteriophage as a biocontrol method for Salmonella on fresh-cut fruit: a model study. J Food Prot 2001; 64: 1116-21.

14.- Modi R, Hirvi Y, Hill A, Griffits M W. Effect of phage on survival of Salmonella Enteritidis during manufacture and storage of cheddar cheese made from raw and pasteurized milk J Food Prot 2001; 64 (7): 927-33.

15.- Kutter E, Sulakvelidze A. Bacteriophages: biology and applications. Taylor \& Francis editors. CRC Press 1st ed. NW, 2005, p. 528.

16.- Ceyssens $P$, Lavigne R. Chapter 2: Introduction to bacteriophage biology and diversity. Sabour $\mathrm{P}$, Griffiths $\mathrm{M}$ editors. Bacteriophages in the control of food-and waterborne pathogens. $1^{\text {st }}$ ed. ASM Press; 2010, p. 11-30.

17.- García P, Rodríguez L, Rodríguez A, Martínez B. Food biopreservation: promising strategies using bacteriocins, bacteriophages and 
endolysins. Trends Food Sci Technol 2010; 21 : 373-82.

18.- Ceyssens P J. Isolation and characterization of lytic bacteriophages infecting Pseudomonas aeruginosa. Tesis para lograr el grado de Doctor en Bioingeniería. Facultad de Bioingeniería, Universidad Católica de Lovaina 2009. 150 p.

19.- Rohwer F. Global phage diversity. Cell 2003; 113: 141.

20.- Hudson J A, Billington C, Carey-Smith G, Greening G. Bacteriophages as biocontrol agents in food. J Food Prot 2005; 68: 426-37.

21.- Hagens S, Loessner M. Application of bacteriophages for detection and control of foodborne pathogens. Appl Microbiol Biotechnol 2007; 76: 513-9.

22.- Dabrowska K, Switala-Jelen K, Opolski A, Weber-Dabrowska B, Gorski A. Bacteriophage penetration in vertebrates. J Appl Microbiol 2005; 98: 7-13.

23.- Skurnik M, Strauch E. Phage therapy: facts and fiction. Int J Med Microbiol 2006; 296: 5-14.

24.- Boyd E F, Brussow H. Common themes among bacteriophage-encoded virulence factors and diversity among the bacteriophages involved. Trends Microbiol 2002; 10: 521-9.

25.- Joerger R D. Alternatives to antibiotics: bacteriocins, antimicrobial peptides and bacteriophages. Poult Sci 2003; 82: 640-7.

26.- Monk A B, Rees C D, Barrow P, Hagens S, Harper D R. Bacteriophage applications: where are we now? Lett Appl Microbiol 2010; 51: 363-9.

27.- Carlton R M, Noordman W H, Biswas B, de Meester E D, Loessner M J. Bacteriophage P100 for control of Listeria monocytogenes in foods: Genome sequence, bioinformatic analysis, oral toxicity study, and application. Regul Toxicol Pharmacol 2005; 43: 301-12.

28.- Hagens S, Loessner M. Bacteriophage for biocontrol of foodborne pathogens: calculations and considerations. Curr Pharm Biotechnol 2010; 11: 58-68.

29.- Hagens S, Offerhaus M. Bacteriophages-new weapons for food safety. Food Technol 2008; 62: 46-54.

30.- Di Giovine M, Salone B, Martina Y, Amati V, Zambruno G, Cundari E, et al. Binding properties, cell delivery, and gene transfer of adenoviral penton base displaying bacteriophage. Virology 2001; 282: 102-12.

31.- García P, Martínez B, Obeso J M, Rodríguez A. Bacteriophages and their application in food safety. Lett Appl Microbiol 2008; 47: 479-85.

32.- Loc-Carrillo C, Abedon S T. Pros and cons of phage therapy. Bacteriophage 2011; 1: 111-4.

33.- Chibeu A, Agius I, Gao A, Sabour P, Kropinski A, Balamurugan S. Efficacy of bacteriophage LISTEXTMP100 combined with chemical antimicrobials in reducing Listeria monocytogenes in cooked turkey and roast beef. Int J Food Microbiol 2013; 167: 208-14.
34.- Kang H W, Kim J W, Jung T S, Woo G J. Wksl3, a new biocontrol agent for Salmonella enterica serovars Enteritidis and Typhimurium in foods: characterization, application, sequence analysis, and oral acute toxicity study. Appl Environ Microbiol 2013; 79: 1956-68.

35.- Soni K, Shen Q, Nannapaneni R. Reduction of Listeria monocytogenes in cold-smoked salmon by bacteriophage $\mathrm{P} 100$, nisin and lauricarginate, singly or in combinations. Int J Food Sci Technol 2014; 49: 1918-24.

36.- Carlton R M. Phage therapy: past history and future prospects. Arch Immunol Ther Exp (Warsz) 1999; 47: 267-74.

37.- Xie H, Zhuang X, Kong J, Ma G, Zhang H. Bacteriophage Esc-A is an efficient therapy for Escherichia coli 3-1 caused diarrhea in chickens. J Gen Appl Microbiol 2005; 51: $159-63$.

38.- Gill J J, Pacan J C, Carson M E, Leslie K E, Griffiths M W, Sabour P M. Efficacy and pharmacokinetics of bacteriophage therapy in treatment of subclinical Staphylococcus aureus mastitis in lactating dairy cattle. Antimicrob Agents Chemother 2006; 50: 2912-8.

39.- Bruttin A, Brüssow H. Human volunteers receiving Escherichia coli Phage T4 orally: a safety test of phage therapy. Antimicrob Agents Chemother 2005; 49: 2874-8.

40.- Sulakvelidze A. Using lytic bacteriophages to eliminate or significantly reduce contamination of food by foodborne bacterial pathogens. J Sci Food Agric 2013; 93: 3137-46.

41.- Payne R J, Jansen V A. Understanding bacteriophage therapy as a density-dependent kinetic process. J Theor Biol 2001; 208: 37-48.

42.- Fiorentin 1, Vieira N D, Barioni J W. Use of lytic bacteriophages to reduce Salmonella Enteritidis in experimentally contaminated chicken cuts. Rev Bras Cien Avic 2005; 7: 255-60.

43.- Higgins J P, Higgins S E, Guenther K L, Huff W, Donoghue A M, Donoghue D J, et al. Use of a specific bacteriophage treatment to reduce Salmonella in poultry products. Poultry Sci 2005; 84: 1141-5.

44.- Filho R, Higgins J, Higgins S, Gaona G, Wolfenden A, Téllez G, et al. Ability of bacteriophages isolated from different sources to reduce Salmonella enterica serovar Enteritidis in vitro and in vivo. PoultSci 2007; 86: 1904-09.

45.- Bigwood T, Hudson J, Billington G, Carey-Smith G, Heinemann J. Phage inactivation of foodborne pathogens on cooked and raw meat. Food Microbiol 2008; 25: 400-6.

46.- Guenther S, Huwyler D, Richard S, Loessner M J. Virulent bacteriophage for efficient biocontrol of Listeria monocytogenes in ready-to-eat foods. Appl Environ Microbiol 2009; 75: 93-100.

47.- Borysowski J, Weber-Dabrowska B. Bacteriophage endolysins as a novel class of antibacterial agents. Exp Biol Med (Maywood) 2008; 231: 366-77.

48.- Leverentz B, Conway W, Camp M, Janisiewicz W, Abuladze T, Yang M, et al. Biocontrol of Listeria monocytogenes on fresh-cut produce by treatment with lytic bacteriophages and a bacteriocin. Appl Environ Microbiol 2003; 69: 4519-26.

49.- Chibeu A, Agius L, Gao A, Sabour P, Kropinski A, Balamurugan S. Efficacy of bacteriophage LISTEXTMP100 combined with chemical antimicrobials in reducing Listeria monocytogenes in cooked turkey and roast beef Int J Food Microbiol 2013; 167: 208-14.

50.- Oliveira M, Viñas L, Colàs $P$, Anguera $M$, Usall J, Abadias M. 2014. Effectiveness of a bacteriophage in reducing Listeria monocytogenes on fresh-cut fruits and fruit juices. Food Microbiol 2014; 38: 137-42.

51.- O'Flynn G, Ross R P, Fitzgerald G F, Coffey A. Evaluation of a cocktail of three bacteriophages for biocontrol of Escherichia coli O157:H7. Appl Environ Microbiol 2004; 70: $3417-24$

52.- Hudson J, Billington C, Cornelius A J, Wilson T, On S L W, Premaratne A, et al. Use of a bacteriophage to inactivate Escherichia coli $\mathrm{O} 157: \mathrm{H} 7$ on beef. Food Microbiol 2013; 36: 14-21.

53.- Hong Y, Pan Y, Ebner P D. Development of bacteriophage treatments to reduce $E$. coli O157:H7 contamination of beef products and produce. J Anim Sci 2014; 92: 1366-77.

54.- Bren L. Bacteria-eating virus approved as food additive. FDA Consum 2007; 41: 20-2.

55.- FDA. Food and Drug Administration, USA. Determination of the GRAS status of bacteriophage P100 as an antimicrobial food ingredient. 2007. http://www.accessdata.fda. gov/scripts/fcn/gras_notices/701456A.pdf [consultado 20 de septiembre de 2014].

56.- OmniLytics. 2007. OmniLytics announces USDA/FSIS allowance for bacteriophage treatment of Salmonella on livestock. 2007. $<$ http://www.omnilytics.com/news/news019. html $>$ [consultado el 23 de octubre de 2014].

57.- Galarce N, Bravo J, Robeson J, Borie C. Bacteriophage cocktail reduces Salmonella enterica serovar Enteritidis counts in raw and smoked salmon tissues. Rev Argent Microbiol 2014; 46: 333-7.

58.- Jorquera D, Navarro C, Rojas V, Turra G, Robeson J, Borie C. The use of a bacteriophage cocktail as a biocontrol measure to reduce Salmonella enteric serovar Enteritidis contamination in ground meat and goat cheese. Biocontrol Sci Techn 2015; 25 : 970-74.

59.- Yévenes K. Bacteriófagos líticos como agentes reductores de contaminación: aplicación en mayonesa casera contaminada con Salmonella Enteritidis. Memoria para optar al Título 
Profesional de Médico Veterinario, Facultad de Ciencias Pecuarias y Veterinarias, Universidad de Chile 2015; pp. 39.

60.- Anany H, Chen W, Pelton R, Griffiths M W. Biocontrol of Listeria monocytogenes and Escherichia coli $\mathrm{O} 157: \mathrm{H} 7$ in meat by using phages immobilized on modified cellulose membranes. Appl Environ Microbiol 2011; 77: 6379-87.

61.- Leverentz B, Conway W S, Camp M J, Janisiewicz W J, Abuladze T, Yang M, et al. Biocontrol of Listeria monocytogenes on fresh-cut produce by treatment with lytic bacteriophages and a bacteriocin. Appl Environ Microbiol 2003; 69: 4519-26.

62.- Sharma M, Patel J R, Conway W S, Ferguson S, Sulakvelidze A. Effectiveness of bacteriophages in reducing Escherichia coli on fresh-cut cantaloupes and lettuce. J Food Prot 2009; 72: 1481-5.

63.- Bigot B, Lee W J, McIntyre L, Hudson J A, Billington C, Heinemann J A. Control of Listeria monocytogenes growth in a ready-to-eat poultry product using a bacteriophage. Food Microbiol 2011; 28: 1448-52.

64.- Kim K P, Klumpp J, Loessner M J. Enterobacter sakazakii bacteriophages can prevent bacterial growth in reconstituted infant formula. Int $\mathbf{J}$ Food Microbiol 2007; 115: 195-203.

65.- Goode D, Allen V M, Barrow P A. Reduction of experimental Salmonella and Campylobacter contamination of chicken skin by application of lytic bacteriophages. Appl Environ Microbiol 2003; 69: 5032-6.

66.- Atterbury R J, Connerton P L, Dodd C E R,
Rees C E D, Connerton L F. Application of host-specific bacteriophages to the surface of chicken skin leads to a reduction in recovery of Campylobacter jejuni. Appl Environ Microbiol 2003; 69: 6302-6.

67.- Whichard J M, Sriranganathan N, Pierson F W. Suppression of Salmonella growth by wild-type and large-plaque variants of bacteriophage Felix $\mathrm{O} 1$ in liquid culture and on chicken frankfurters. J Food Prot 2003; 66: 220-5.

68.- Guenther S, Loessner M. Bacteriophage biocontrol of Listeria monocytogenes on soft ripened white mold and red-smear cheeses. Bacteriophage 2011; 1: 94-100.

69.- Labrie S J, Samson J E, Moineau S. Bacteriophage resistance mechanisms. Nat Rev Microbiol 2010; 8: 317-27.

70.- Buckling A, Brockhurst M. Bacteria-virus coevolution. Adv Exp Med Biol 2012; 751: 347-70.

71.- Nechaev S, Severinov K. The elusive object of desire-interactions of bacteriophages and their hosts. Curr Opin Microbiol 2008; 11: 186-93.

72.- Bikard D, Marraffini L A. Innate and adaptive immunity in bacteria: mechanisms of programmed 31 genetic variations to fight bacteriophages. Curr Opin Immunol 2011; 24: 15-20.

73.- Martínez-Borra J, González S, López-Larrea C. The origin of the bacterial immune response. Adv Exp Med Biol 2012; 738: 1-13.

74.- Sashital D G, Wiedenheft B, Doudna J A. Mechanism of foreign DNA selection in a bacterial adaptive immune system. Mol Cell 2012; 46: 606-15.
75.- Stern A, Sorek R. The phage-host arms race: shaping the evolution of microbes. Bioessays 2011; 33: 43-51.

76.- O'Flynn G, Ross R P, Fitzgerald G F, Coffey A. Evaluation of a cocktail of three bacteriophages for biocontrol of Escherichia coli O157:H7. Appl Environ Microbiol 2004; 70: 3417-24.

77.- Farfán F. 2009. Efecto de una mezcla de tres bacteriófagos en la reducción de Salmonella Enteritidis en huevos SPF experimentalmente infectados. Memoria para optar al Título de Médico Veterinario. Facultad de Ciencias Veterinarias y Pecuarias, Escuela de Ciencias Veterinarias, Universidad de Chile. 69 pp.

78.- Mahony J, McAuliffe O, Ross R P, Van Sinderen D. Bacteriophages as biocontrol agents of food pathogens. Curr Opin Biotech 2011; 22: $157-63$.

79.- Martínez B, Obeso J M, Rodríguez A, García P. Nisin-bacteriophage cross resistance in Staphylococcus aureus. Int J Food Microbiol 2008; 122: 253-8.

80.- Holck A, Berg J. Inhibition of Listeria monocytogenes in cooked ham by virulent bacteriophages and protective cultures. Appl Environ Microbiol 2009; 75: 6944-6.

81.- O'Mahoney J, McAuliffe O, Ross P, van Sinderen D. Bacteriophages as biocontrol agents of food pathogens. Curr Opin Biotechnol 2011; 22: 157-63.

82.- Endersen L, O’Mahony J, Hill C, Ross P, McAuliffe O, Coffey A. Phage therapy in the food industry. Annu Rev Food Sci Technol 2014; 5: 327-49. 